\title{
Influence of Interface Bond Damage on the Mechanical Properties of CRTS III Slab Track
}

\author{
Kunteng Zhu ${ }^{1,2, a}$, Zhiping Zeng ${ }^{1,2, b^{*}}$, Bin $\mathrm{Wu}^{1, \mathrm{c}}$ and Wei Wei ${ }^{1, \mathrm{~d}}$ \\ ${ }^{1}$ Central South University, Changsha, Hunan, China \\ ${ }^{2}$ National Engineering Laboratory for High-Speed Railway Construction, Changsha, China \\ a306353043@qq.com, b956310155@qq.com, c2747958853@qq.com, d645984212@qq.com
}

Keywords: CRTS III slab track; Finite element; Interface bond damage; Force change

\begin{abstract}
The interface bond damage between the slab and self-compaction concrete is one of the most common damages of CRTSIII slab track. According to the CRTSIII slab track structure characteristics, an finite element mechanical analysis model of track structure was established, which include rail, track slab, door type steel, self-compaction concrete and base. Furthermore, the influence of interface bond damage on the mechanical properties of CRTSIII slab track was analyzed. Results show that compared with interface in good condition, the stress of track structure increased with the increase of the length of interface bond damage. Among them, the range of interface vertical stress, track slab and self-compaction concrete stress remarkable increased. Under train load, the maximum increase range of track structure stress was up to 9 times compared with interface in good condition. Under temperature gradient load, the maximum increase range of track structure stress was up to 2.4 times compared with interface in good condition. Under train and temperature gradient coupling loads, the maximum increase range of track structure stress was up to 11 times compared with interface in good condition.
\end{abstract}

\section{Introduction}

The application time of CRTSIII slab track is short in China, and its stability is widely concerned by scholars [1-3]. A series of tests were carried out to improve the stability of CRTS III slab track by China Academy of Railway Sciences [4]. In order to improve the adaptability of the structure, expand the applicable scope and meet the requirement of the intercity railway at speed of $200 \mathrm{~km} / \mathrm{h}$ or above, the design of CRTS III slab track, measurement and construction technologies were deeply researched by Li Yangcun [5]. A spatial model for static analysis of CRTS III slab track on roadbed was established by finite element software, and a vehicle-track coupling dynamic model was established by FOSYS, a dynamic analysis procedure developed by Wang $\mathrm{Pu}$ [6]. The statics and dynamics characteristics of track structure were compared in the cases of two main setting schemes of the recesses. However, owing to the shrinkage of self-compacting concrete, construction process, external environment and train load, the interface between track slab and self-compacting concrete is easy to produce bond damage [7]. In this paper, a model for analysis of CRTS III slab ballastless track on roadbed was established by finite element software according to the CRTS III track slab structure characteristics [8]. Meanwhile, the influence of interface bond damage on the CRTS III slab ballastless track structure were studied.

\section{Calculation Model and Parameters}

In order to study on the interstratal mechanical characteristics of track structure, a model for analysis of CRTSIII slab track on roadbed was established by finite element software. Among them, rail was simulated by beam element and track slab, self compacting concrete and base were simulated by 3D solid element[9-10], as shown in Fig. 1. Owing to interstratal effect was considered, transverse reinforcement of door type steel was ignored. Therefore, a door type steel was simplified to two pin, 
and door type steel was simulated by beam element. Constraint equation was constructed between door type steel and concrete in this finite model as shown in Fig. 2.

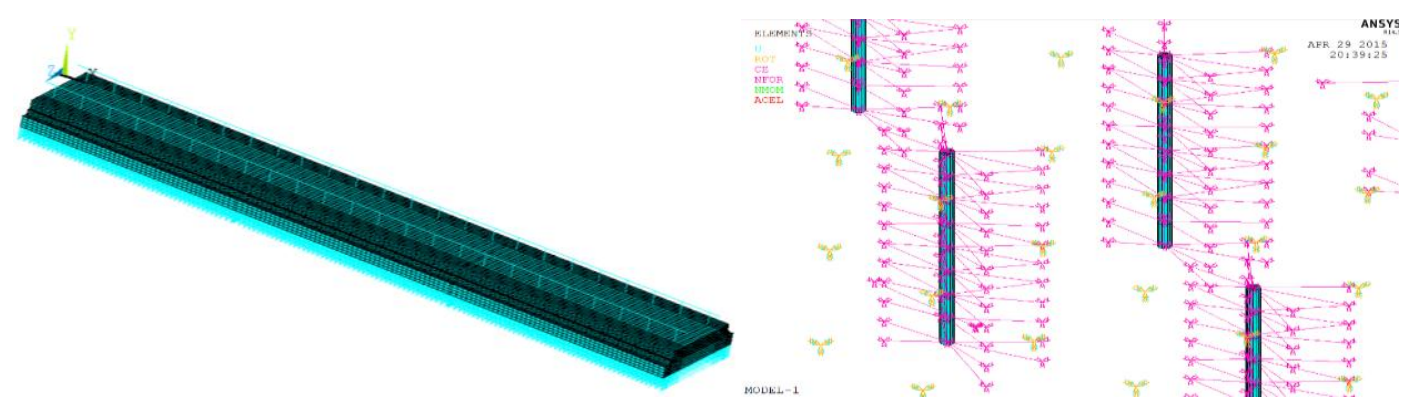

Figure 1. Finite element model Figure 2. Constraint model of door type steel

\section{Debonding Cases}

Owing to the randomness of concrete structure, debonding position may exist anywhere in the interface between track slab and self-compacting concrete. According to locale survey and references [6], the cases of interface bond damage were divided into debond under edge of track slab, debond under central of track slab and debond under rail as shown in Fig. 3. The debonging longitudinal length of three cases are $0.28 \mathrm{~m}, 0.91 \mathrm{~m}, 1.54 \mathrm{~m}, 2.17 \mathrm{~m}, 2.8 \mathrm{~m}, 3.43 \mathrm{~m}, 4.06 \mathrm{~m}, 4.69 \mathrm{~m}, 5.32 \mathrm{~m}, 5.6 \mathrm{~m}$. In order to comprehensive illustrate the influence of interface bond damage on mechanical characteristic, train load, temperature gradient load and coupling load are considered to calculate.

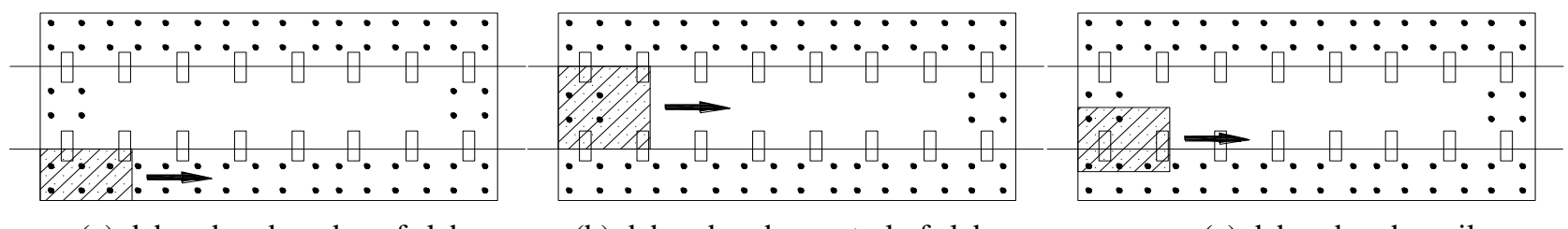

(a) debond under edge of slab

(b) debond under central of slab

(c) debond under rail

Figure 3. Debonding conditions

\section{Influence of Interface Bond Damage on Mechanical Characteristic}

Influence of Interface Bond Damage on Mechanics Characteristic under Train Load. Preceding theory and debonding conditions are considered to calculate the influence of interface bond damage under train load. However, the length of article is limited. Therefore, representative figures are listed as shown in Fig. 4 Fig. 6. Calculation shows that under train load, three debonding conditions are easy to cause remarkable changes of track structure stress. Among them, transversal and longitudinal tensile stress of track slab, transversal and longitudinal compression stress of self-compacting concrete and interface compression stress significantly increase. Compared with interface in good condition, the maximum change range up to 9 times. 


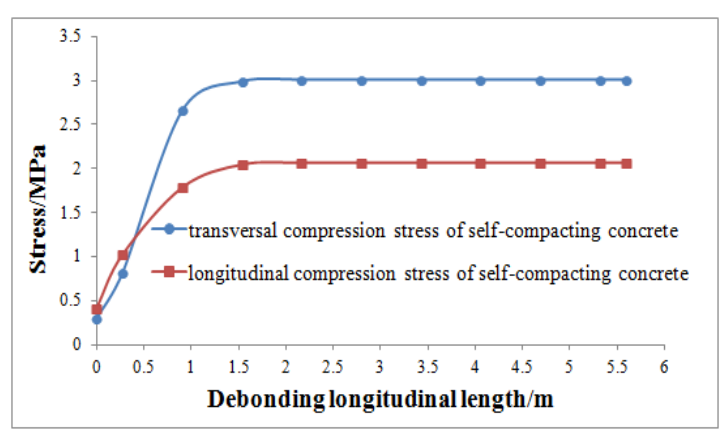

(a) compression stress of self-compacting concrete

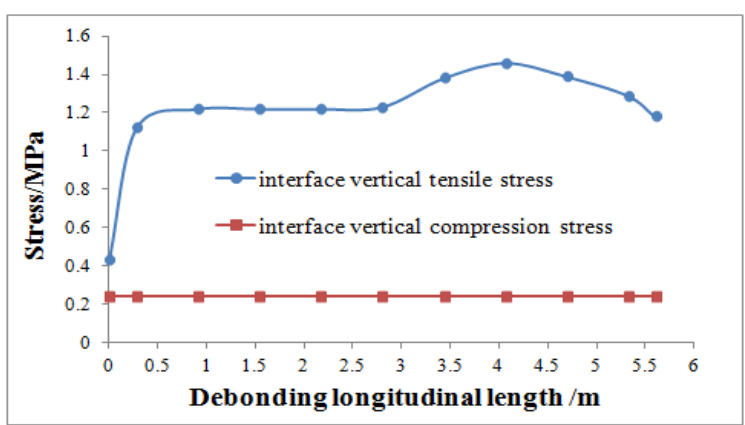

(b) interface vertical stress

Figure 4 . When the bond under edge of the slab is damaged, the change rule of track structure

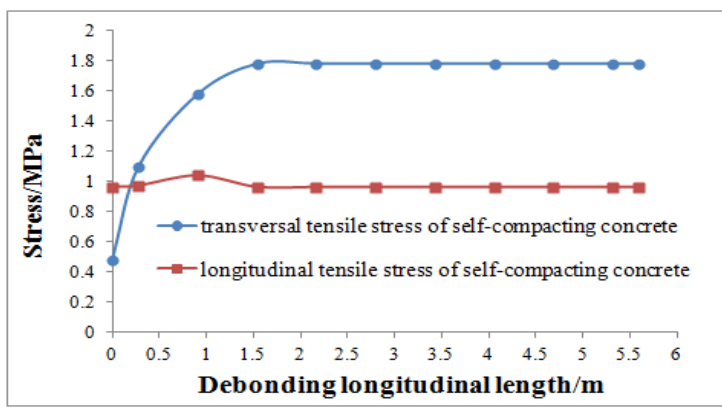

(a) tensile stress of self-compacting concrete

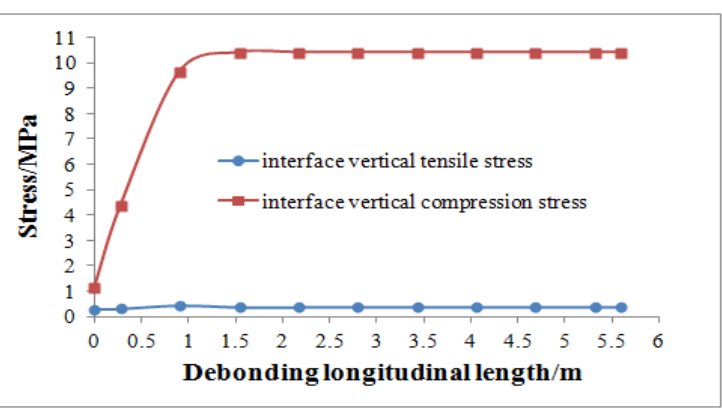

(b) interface vertical stress

Figure 5. When the bond under middle of the slab is damaged, the change rule of track structure

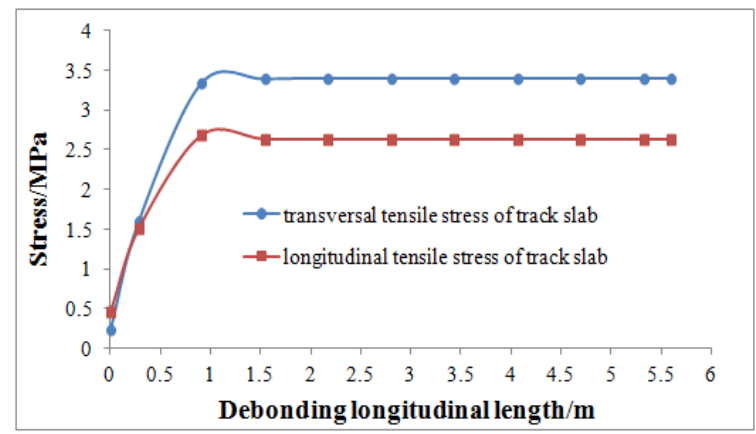

(a) tensile stress of track slab

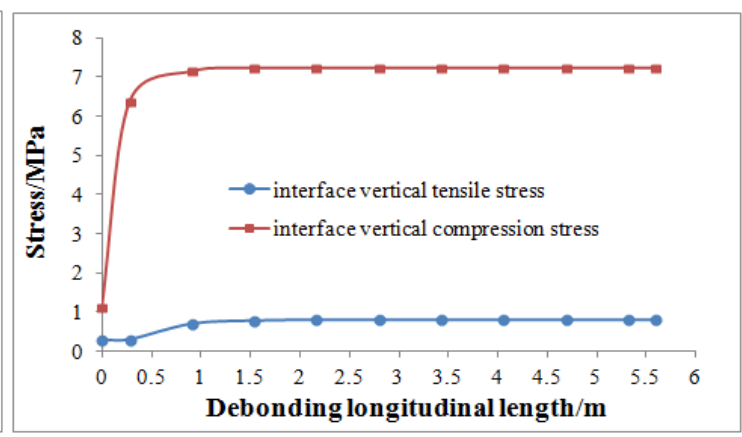

(b) interface vertical stress

Figure 6. When the bond under rail of the slab is damaged, the change rule of track structure

Influence of Interface Bond Damage on Mechanics Characteristic under Temperature Gradient Load. Preceding theory and debonding conditions are considered to calculate the influence of interface bond damage under temperature gradient load. However, the length of article is limited. Therefore, representative figures are listed as shown in Fig. 7 Fig. 9. Calculation shows that under negative temperature gradient load, the vertical tensile stress near the debonding area under edge of slab significantly increased. Under positive temperature gradient load, the tensile stress near the debonding area under middle of slab and rail significantly increased. Compared with interface in good condition, the maximum change range up to 2.4 times. 


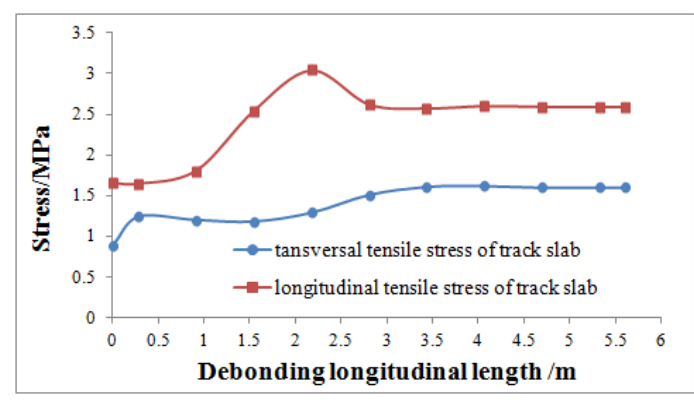

(a) compression stress of self-compacting concrete

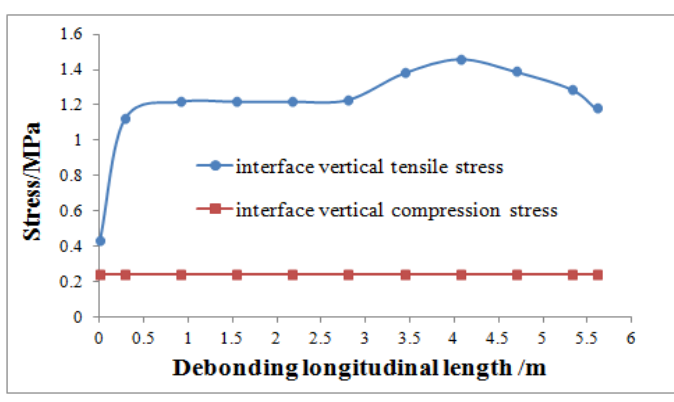

(b) interface vertical stress

Figure 7. When the bond under edge of the slab is damaged, the change rule of track structure

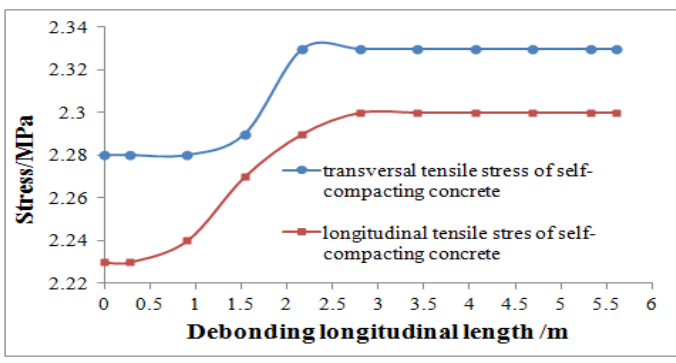

(a) compression stress of self-compacting concrete

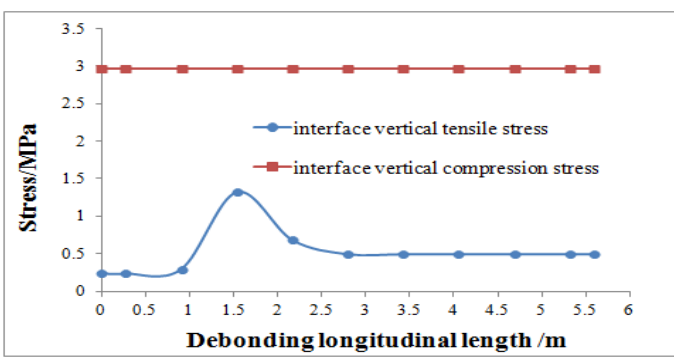

(b) interface vertical stress

Figure 8 . When the bond under middle of the slab is damaged, the change rule of track structure

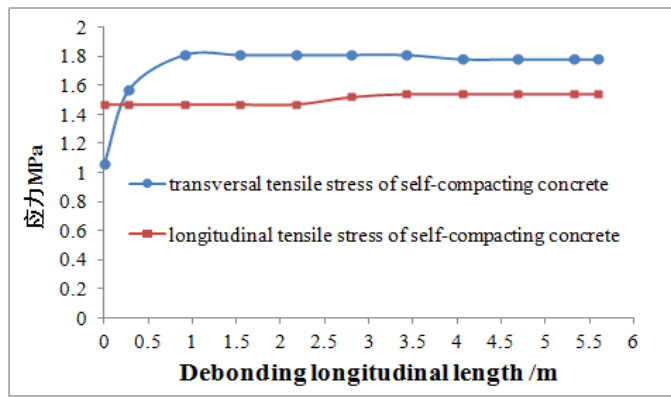

(a) tensile stress of self-compacting concrete

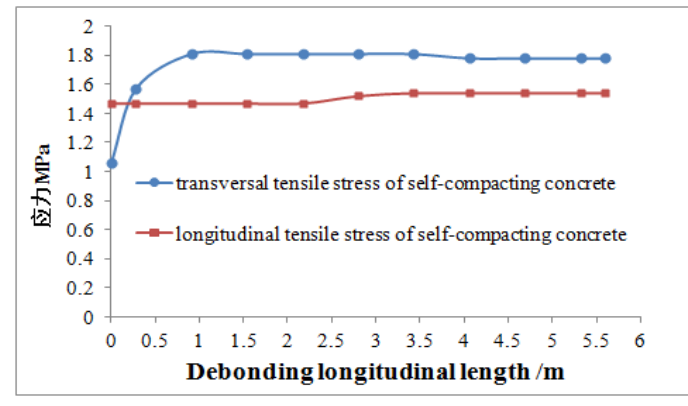

(b) compression stress of self-compacting concrete

Figure 9. When the bond underrail of the slab is damaged, the change rule of track structure

Influence of Interface Bond Damage on Mechanics Characteristic under Coupling load. Preceding theory and debonding conditions are considered to calculate the influence of interface bond damage under coupling load. However, the length of article is limited. Therefore, representative figures are listed as shown in Fig. 10 Fig. 11. Calculation shows that under coupling load, three debonding conditions are easy to cause remarkable changes of track slab stress. When the bond under edge of slab is damaged, transversal and longitudinal tensile stress of self-compacting concrete significantly increased. However, when the bond under edge middle of slab and rail are damaged, transversal and longitudinal stress of self-compacting concrete significantly increased. Compared with train load and temperature gradient load, under coupling load, interface vertical tensile stress increases more significantly. Compared with interface in good condition, the maximum change range up to 11 times. 


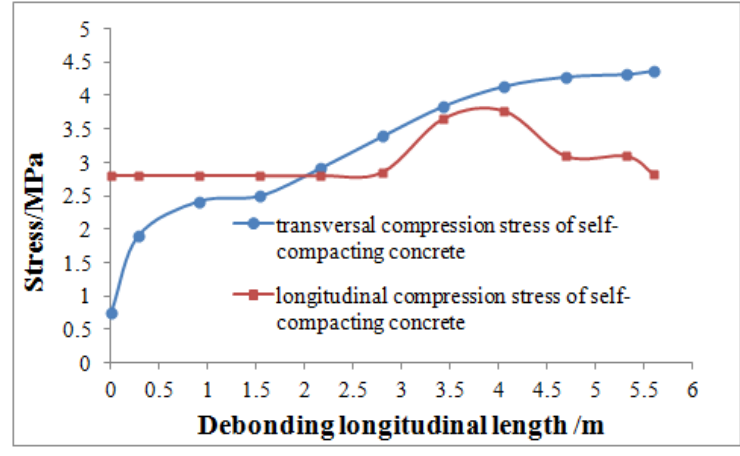

(a) compression stress of self-compacting concrete

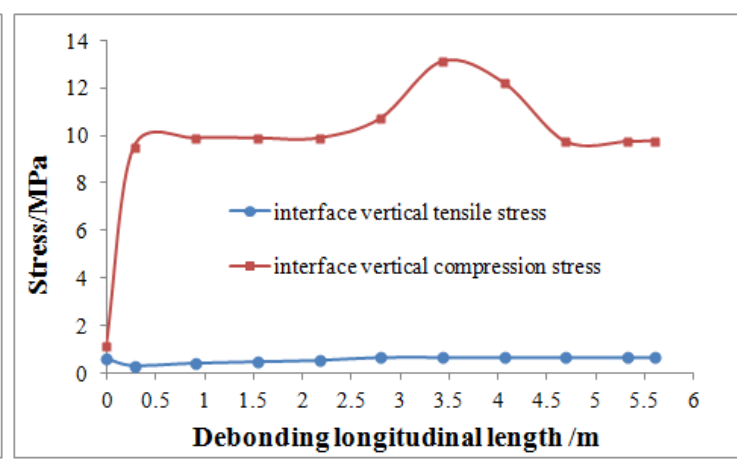

(b) interface vertical stress

Figure 10. When the bond under edge of the slab is damaged, the change rule of track structure

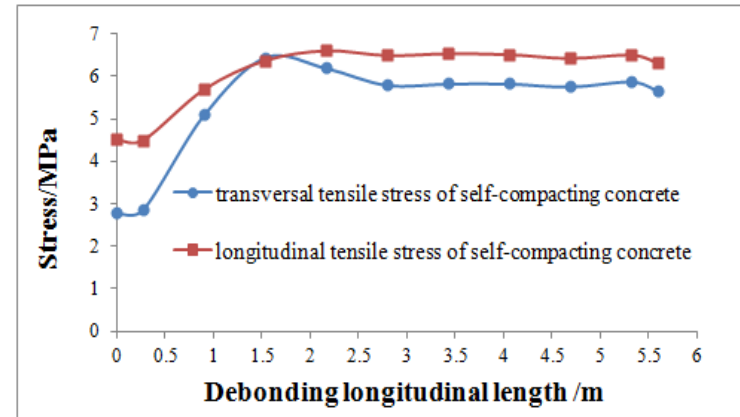

(a) tensile stress of self-compacting concrete

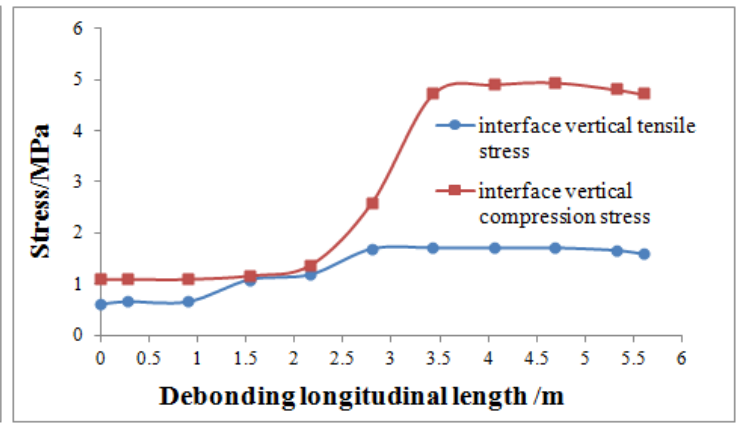

(b) interface vertical stress

Figure 11. When the bond under middle of the slab is damaged, the change rule of track structure

\section{Conclusions}

1. Compared with interface in good condition, the stress of track structure increased with the increase of the length of interface bond damage. Among them, the range of interface vertical stress, track slab and self-compaction concrete stress remarkable increased.

2. Under train load, the maximum increase range of track structure stress was up to 9 times compared with interface in good condition. Under temperature gradient load, the maximum increase range of track structure stress was up to 2.4 times compared with interface in good condition. Under train and temperature gradient coupling loads, the maximum increase range of track structure stress was up to 11 times compared with interface in good condition.

3. When water and train impact load are considered, the influence of interface bond damage on the mechanical properties of CRTS III slab track needs further study.

\section{Acknowledgements}

The research described in this paper was financially supported by the Science and Technology Foundation of China Railway Corporation (Grant No. 2014G001-D); the Joint Fund of the National Natural Science Foundation of China (Grant No. U1334203); the National Natural Science Foundation of China (Grant No. 51378513); the Project of Innovation-driven Plan in Central South University (2015CXS014).

\section{References}

[1] GAO Liang, ZHAO Lei, QU Cun, CAI Xiaopei. Analysis on Design Scheme of CRTS III Type Slab Ballastless Track [J]. Journal of Tongji University (Natural Science), 2013, 41(6): 848-855. 
[2] WEI Hedao. Research on the Structure Design of New Unit Slab Ballastelss Track on the Zhengzhou-Xuzhou Railway Passenger Dedicated Line[D]. Changsha: Central South University, 2013.

[3] MAN Kunlin, LONG Guangcheng, Xie Youjun. Carbonation and Mechanics Evolvement of Self-consolidating Concrete Used in CRTS III Type Slab Ballastless Track Filling Layer [J]. Journal of Railway Science and Engineering, 2012, 9(6): 42-47.

[4] China Academy of Railway Sciences, Central South University. Performance Test Research of CRTSIII Type Slab Ballastless Track Structures under Service State. Beijing: China Academy of Railway Sciences, 2015.

[5] LI Yangcun. CRTSIII Type Slab Track Technology Applied in Wuhan to Xianning Intercity Railway [J]. Journal of Railway Engineering Society, 2013, 15(4): 51-55.

[6] WANG Pu, GAO Liang, ZHAO Lei, QUN Cun. Study on Setting Method of Position-limitation Recess of CRTS III Type Slab Ballastless Track [J]. Engineering Mechanics, 2014, 31(2):110-115.

[7] YANG Zheng. Mechanics and Maintenance Standards of Connection Damage for CRTS III Slab Track [D]. Chengdu: Southwest Jiaotong University, 2011.

[8] China Academy of Railway Sciences. General Reference Map of High Speed Railway CRTS III Type Slab Ballastless Track Structures[S]. Beijing: China Academy of Railway Sciences, 2015.

[9] WANG Yuhang, WANG Jijun. Multi-scale Finite Element Model for CRTS III Type Slab Ballastless Track Structures [J]. Journal of Railway Science and Engineering, 2015, 12(3): 468-474.

[10] WANG Xinmin. Numerical Analysis of Ansys Engineering structure [M]. Beijing: China Communications Press, 20 